\title{
Loïc Artiaga, Des Torrents de papier. Catholicisme et lectures populaires au XIX $X^{\mathrm{e}}$ siècle
}

\section{Marco Stupazzoni}

\section{(2) OpenEdition}

\section{Journals}

\section{Edizione digitale}

URL: http://journals.openedition.org/studifrancesi/8284

DOI: 10.4000/studifrancesi.8284

ISSN: 2421-5856

\section{Editore}

Rosenberg \& Sellier

\section{Edizione cartacea}

Data di pubblicazione: 1 mai 2009

Paginazione: 183-184

ISSN: 0039-2944

\section{Notizia bibliografica digitale}

Marco Stupazzoni, «Loïc Artiaga, Des Torrents de papier. Catholicisme et lectures populaires au xix siècle», Studi Francesi [Online], 157 (LIII | I) | 2009, online dal 30 novembre 2015, consultato il 10 janvier 2021. URL: http://journals.openedition.org/studifrancesi/8284 ; DOI: https://doi.org/10.4000/ studifrancesi.8284

Questo documento è stato generato automaticamente il 10 janvier 2021.

\section{(c) $($ ) $(9)$}

Studi Francesi è distribuita con Licenza Creative Commons Attribuzione - Non commerciale - Non opere derivate 4.0 Internazionale. 


\title{
Loïc Artiaga, Des Torrents de papier. Catholicisme et lectures populaires au $\mathrm{XIX}$ siècle
}

\author{
Marco Stupazzoni
}

\section{NOTIZIA}

LOÏC ARTIAGA, Des Torrents de papier. Catholicisme et lectures populaires au XIX siècle, préface de Jean-Yves Mollier, Limoges, P.U.L.I.M., 2007, «Médiatextes», pp. 193.

1 Particolarmente intensa e tenace è stata, nel corso di tutto il xIX secolo, la vigile azione repressiva condotta dalla Chiesa cattolica contro il romanzo e contro la sua diffusione, in quanto espressione più riuscita ed efficace di una connotazione sempre più industriale e transnazionale del marcato librario, nei diversi strati della società civile. Soprattutto tra il 1830 e il 1864 , la violenta condanna della produzione romanzesca "popolare" da parte dell'autorità romana, di cui il decreto dell'indice del 20 giugno 1864 costituisce la testimonianza più rilevante, si colloca a pieno titolo «dans une logique d'action de l'Église catholique et de ses fidèles dans le monde de la lecture et de la librairie» $\mathrm{e}$ «s'accompagne de son utilisation à des fins de propagande» (p. 17). Fin dalla sua «proto-histoire», la cultura mediatica «est investie par l'Église catholique, qui en définit les contours en usant des métaphores apocalyptiques ou en condamnant les nouveautés littéraires, mais en utilise en même temps les vecteurs» (p. 167).

2 In questo volume, L. Artiaga conduce uno studio documentato e di ampio respiro sui rapporti tra la cultura cattolica e la cosiddetta letteratura industriale mettendo in evidenza i caratteri e le dinamiche che hanno alimentato il dialogo permanente tra la «sphère de l'orthodoxie et celle de l'orthopraxie de la lecture» (p.168). Partendo da un'analisi attenta del ruolo svolto, soprattutto nella prima metà dell'Ottocento, dalla Sacra Congregazione dell'Indice nell'azione di sorveglianza e di controllo della diffusione del romanzo, l'autore indaga successivamente sull'evoluzione delle diverse 
strategie medianiche adottate dalle istituzioni ecclesiastiche non solo per selezionare $\mathrm{i}$ prodotti culturali, ma per inquadrare e reinvestire i modelli, le forme e le strategie della letteratura industriale in strumenti di apostolato soprattutto grazie alla creazione delle biblioteche parrocchiali. Il passaggio da una "censure "sèche" au filtrage et à la régulation s'accompagne d'un travail sur les lecteurs et leur mode d'appréhension du livre. Les romans distribués contiennent des informations sur la posture, les temps de lecture, la manière de lire. Le clergé responsable du mouvement des "bons" livres présente ces ouvrages comme des fictions innocentes, qui, à l'insu des lecteurs, diffusent un message religieux» (p. 170).

Nella prima parte del volume, dove l'autore fornisce uno studio preciso dei contenuti, degli stili e delle immagini presenti nei giudizi formulati dai diversi consultori in relazione alle loro richiesta di condanna e di proibizione di alcune opere di scrittori francesi dell'Ottocento, un intero capitolo è dedicato a Balzac e ai romanzi della Comédie humaine («Le quadruple examen de Balzac», pp.51-65), messi all'Indice con tre successivi decreti tra il settembre 1841 e l'aprile 1842 e successivamente nel già citato "Decretum" del giugno 1864. I riferimenti alla filosofia di Swedenborg e al magnetismo animale, l'abuso del lessico religioso riferito a personaggi, luoghi e situazioni immorali, il disprezzo della religione e dell'autorità ecclesiastica e l'esaltazione dell'elemento criminogeno della società sono soltanto alcune delle argomentazioni più evidenti $\mathrm{e}$ ritenute sufficientemente valide per condannare senza appello le opere narrative dello scrittore francese (cfr., in appendice, i passaggi relativi al Lys dans la vallée e all'Histoire des Treize riportati integralmente dall'autore). Si tratta senza alcun dubbio, precisa L. Artiaga, di una lettura riduttiva, a senso unico dei testi balzachiani: «il ne s'agit pas d'envisager le texte comme une œuvre littéraire, de se perdre dans les artifices du roman et les ornements du style» (p. 57): si tratta, al contrario, di una insanabile frattura strutturale e culturale che separa «les lecteurs romains et l'écriture romanesque», poiché «c'est le statut même de la fiction qui ne peut s'accorder avec la représentation du texte qu'ont les consulteurs» (p. 63). 